Farum

Sociológico

\section{Forum Sociológico}

Série II

39 | 2021

Covid-19: Acesso a direitos, desigualdades sociais e (re)arranjos institucionais no controle da pandemia em Portugal e no Brasil

\title{
A situação de vulnerabilidade dos povos indígenas do Mato Grosso e em especial dos Xinguanos frente à Covid-19 e às omissões estatais
}

The situation of vulnerability of indigenous communities and special case of Xinguanos against Covid and due to state omissions

Cláudia Maria Guimarães Lopes de Castro, Vívian Lara Cáceres Dan, Évelin Mara Cáceres Dan e Eduarda Cristine Pedro Arruda

\section{(2) OpenEdition Journals}

Edição electrónica

URL: https://journals.openedition.org/sociologico/10265

DOI: $10.4000 /$ sociologico.10265

ISSN: $2182-7427$

Editora

CICS.NOVA - Centro Interdisciplinar de Ciências Sociais da Universidade Nova de Lisboa

Edição impressa

Paginação: 53-64

ISSN: 0872-8380

Refêrencia eletrónica

Cláudia Maria Guimarães Lopes de Castro, Vívian Lara Cáceres Dan, Évelin Mara Cáceres Dan e

Eduarda Cristine Pedro Arruda, «A situação de vulnerabilidade dos povos indígenas do Mato Grosso e em especial dos Xinguanos frente à Covid-19 e às omissões estatais», Forum Sociológico [Online], 39 | 2021, posto online no dia 23 novembro 2021, consultado o 29 março 2022. URL: http://

journals.openedition.org/sociologico/10265 ; DOI: https://doi.org/10.4000/sociologico.10265 


\title{
A SITUAÇÃO DE VULNERABILIDADE DOS POVOS INDÍGENAS DO MATO GROSSO E EM ESPECIAL DOS XINGUANOS FRENTE À COVID-19 E ÀS OMISSÕES ESTATAIS
}

\author{
THE SITUATION OF VULNERABILITY OF INDIGENOUS COMMUNITIES AND SPECIAL CASE \\ OF XINGUANOS AGAINST COVID AND DUE TO STATE OMISSIONS
}

https://doi.org/10.4000/sociologico.10265

Cláudia Maria Guimarães Lopes de Castro

- Secretaria de Saúde do Estado de Mato Grosso, Cáceres, Brasil. ORCID: http://orcid.org/0000-0001-6074-5424

Vívian Lara Cáceres Dan

- Universidade do Estado de Mato Grosso Carlos Alberto Reyes Maldonado (UNEMAT), Faculdade de Ciências Exatas e Tecnológicas, Barra do Bugres, Brasil. ORCID: http://orcid.org/0000-0001-9880-3028

Évelin Mara Cáceres Dan

Universidade do Estado de Mato Grosso Carlos Alberto Reyes Maldonado (UNEMAT), Faculdade de Ciências Exatas e Tecnológicas, Barra do Bugres, Brasil. ORCID: http://orcid.org/0000-0001-9960-6325

Eduarda Cristine Pedro Arruda

universidade do Estado de Mato Grosso Carlos Alberto Reyes Maldonado (UNEMAT), Faculdade de Ciências Exatas e Tecnológicas, Barra do Bugres, Brasil. ORCID: http://orcid.org/0000-0001-8111-5181

\begin{abstract}
Resumo
Fica evidente a situação de omissão do governo brasileiro em relação às comunidades indígenas e, atualmente ainda mais, à disseminação do novo coronavírus nas aldeias de todo o Brasil. O presente artigo pretende analisar a situação epidemiológica e as ações do Estado em relação ao combate a esse vírus dentro das aldeias dos povos indígenas do estado de Mato Grosso. A pesquisa é de natureza quanti-qualitativa, de cunho bibliográfico, com análise de documentos como boletins epidemiológicos, tabelas produzidas a partir desses dados, planos de enfrentamento a covid-19 e legislação pertinente com a seguinte problemática: que medidas têm sido tomadas pelo Estado para o enfrentamento desse vírus, especificamente em relação aos Distritos Sanitários Especiais Indígenas (DSEI), e qual o alcance das mesmas para amenizar a disseminação de casos de covid-19 nas aldeias dos povos indígenas do Mato Grosso? Esse arcabouço metodológico foi complementado com dados quantitativos dos boletins epidemiológicos disponibilizados pelo DSEI Xingu-MT referentes ao período de 21 de setembro a 5 de outubro de 2020 e dados disponibilizados pela Articulação dos Povos Indígenas do Brasil (APIB), de março de 2020 a março de 2021, fornecendo um panorama de casos e óbitos da covid-19 em relação aos povos indígenas do Mato Grosso. Desse modo, conclui-se que o viés omisso do Estado e a falta de estrutura adequada resultam na falta de planejamento e eficácia de ações protetivas para o enfrentamento do coronavírus nas comunidades indígenas do Mato Grosso.
\end{abstract}

Palavras-chave: indígenas, pandemia, Governo brasileiro, vulnerabilidade

\section{Abstract}

It is evident the situation of neglect of the Brazilian Government in relation to the indigenous communities and, even more so today, with the spread of the new coronavirus in the villages of all Brazil. In detriment of this, the present article intends to analyze the epidemiological situation and actions taken by the government related to the fight against the virus in the villages of the indigenous people in the state of Mato Grosso. The research is based on quantitative, qualitative and bibliographic research, with analysis of documents such as epidemiological bulletins, tables 
produced from these data, plans to confront the Covid-19 and pertinent legislation with the following problem: what measures have been taken by the government to cope with the virus related specifically to Special Sanitary Districts and how far is their coverage to mitigate the spread of Covid-19 cases in the villages? This methodological framework was complemented with quantitative data from the epidemiological bulletins provided by DSEI Xingu-MT dating from 9/21 to $10 / 5 / 2020$ and by information released by the Articulation of Indigenous People of Brazil, providing an annual overview of cases and deaths of Covid-19 of indigenous people from Mato Grosso. Thus, it is concluded that the omission and negationist bias adopted by the federal government resulted in the lack of planning and effectiveness of protective actions to confront coronavirus in indigenous communities.

Keywords: indigenous, pandemic, Brazilian Government, vulnerability

\section{Introdução}

Nos últimos 20 anos, a Síndrome Respiratória Aguda Grave (SARS) vem sendo responsável por epidemias virulentas. Uma nova cepa denominada Síndrome Respiratória do Oriente Médio (MERS), emergiu na China, em 2003, e na Arábia Saudita, em 2012, e em dezembro de 2019, o vírus sofreu mutações e o SARS-CoV-2 ganhou características agressivas, aumentando o seu potencial de letalidade (Mahase, 2020).

A acelerada disseminação geográfica do novo coronavírus resultou em um Decreto da World Health Organization (WHO), em 11 de março de 2020, que estabeleceu que o atual surto epidemiológico é uma pandemia. Posteriormente, o Senado Federal homologou o projeto legislativo que decretava estado de calamidade pública no Brasil a partir do Decreto n. ${ }^{0} 06$, de 18 de março de $2020^{1}$. Compreende-se, portanto, que esta epidemia parte de uma cartografia universal de contágio, sem distinções de raça, classe social ou credo. Entretanto, ela condena grupos minoritários, como é o caso de povos indígenas, cujas condições de acesso à assistência médica, estrutura de atendimento e insumos necessários à saúde e segurança alimentar são desiguais; além disso, diverge do ideal democrático, se tornando mais uma epidemia onde a taxa de letalidade em relação aos indígenas é relatada pelos jornais como no mínimo o dobro da do resto da população².

É indubitável que a história dos povos indígenas sempre esteve atrelada a surtos epidêmicos e, segundo o antropólogo Fausto (2020): "Desde o início da colonização, [os povos indígenas] tiveram que aprender em seus corpos o que é uma epidemia". Desse modo, a pandemia da covid-19 faz renascer um "medo ancestral" daqueles que resistiram aos vários episódios de surtos epidêmicos, expondo suas vulnerabilidades tanto pela precariedade de acesso ao sistema de saúde e sua estrutura insuficiente, como pelo modo de vida comunitário nas aldeias e rituais tradicionais, que se destacam como empecilhos diante da necessidade de isolamento social devido a recente crise sanitária.
Ademais, não somente os impactos do coronavírus são lesivos, como um histórico de políticas anti-indígenas ${ }^{3}$ vem sendo estruturado antes e durante o contexto pandêmico, priorizando a desconstrução de direitos fundamentais garantidos pela ordem jurídica e configurando "violência institucional legislativa à interpretação constitucional nucleada pela diversidade cultural" (Albuquerque, 2020, p. 78). Enfatiza-se a dificuldade de acesso a esses dados específicos sobre a covid-19 em relação aos indígenas - povos afetados, número de casos por aldeia e DSEI vinculados -, onde a própria Articulação dos Povos Indígenas do Brasil (APIB) relata a "falta de transparência" na identificação dos casos onde os óbitos aconteceram e também dificuldades de acesso aos dados sobre a covid-19 entre seus povos, sendo por eles caracterizado como "racismo institucional" praticado pela Secretaria Especial de Saúde Indígena (SESAI)4. Os dados disponíveis no site da APIB é um resumo de casos registrados pelo Comitê Nacional de Vida e Memória Indígena (CNVMI) em todo o país dividido por estados brasileiros ${ }^{5}$.

Partindo do evidente descaso em relação às populações indígenas, o presente trabalho concentra-se na análise do avanço da covid-19 nos territórios indígenas do estado de Mato Grosso, no recorte anual entre os períodos de março de 2020 a março de 2021, verificando a taxa de letalidade do vírus e a efetividade das políticas públicas adotadas para mitigar os impactos do coronavírus nesses povos. O trabalho assenta nos estudos de documentos oficiais como os Planos de Contingência Nacional para infecção humana pelo novo coronavírus em povos indígenas do Governo Federal, o plano específico do Distrito Sanitário Indígena do Xingu (DSEI Xingu) e o da Federação dos Povos e Organizações Indígenas do Mato Grosso (FEPOIMT), bem como nos dados epidemiológicos fornecido pela APIB e ainda nos dados relativos a um período curto, de 21/09 a $05 / 10 / 2020$, em que foram disponibilizados dados estatístico sobre o avanço da epidemia pelo DSEI Xingu. Ao solicitarmos informações sobre a suspensão do envio desses dados, não houve explicação 
sobre o motivo de não terem mais enviado dados de contágio de suas aldeias para nosso projeto de pesquisa Observatório de Políticas Públicas sobre a Covid-19 para povos e comunidades tradicionais, vinculado ao curso de Direito da Universidade do Estado de Mato Grosso (UNEMAT).

Aplica-se como metodologia de trabalho a pesquisa bibliográfica e documental para alcançar os objetivos de compreender a categoria de vulnerabilidades, bem como os aportes protetivos e dados acessados. A pesquisa também se baseia nos materiais publicados em artigos científicos, revistas e jornais, recorrendo-se a conteúdos acessíveis veiculados digitalmente e incluindo a análise dos dados divulgados pela APIB e pelo DSEI Xingu.

\section{Aspectos epidemiológicos, culturais, territoriais, sociais e estruturais das vulnerabilidades dos povos indígenas frente à pandemia}

Segundo a World Health Organization (WHO), a pandemia é caracterizada por uma disseminação global de uma nova doença e esse conceito foi atribuído recentemente ao SARS-CoV-2, causador da covid-19. O comportamento viral do novo coronavírus impactou, e ainda impacta mundialmente, por se tratar de uma síndrome respiratória aguda grave (SRAG) em que a transmissão é feita predominantemente pelo ar; o vírus tem sofrido mutações, o que aumenta os índices de propagação entre a população e propicia um colapso no sistema de saúde, uma vez que faltam estrutura física, materiais e recursos humanos para atender a explosão de inúmeros casos. No Brasil, país marcado pela desigualdade social, a crise sanitária intensificou a discrepância histórica que as populações mais vulneráveis vivenciam.

Segundo Sato (2020), o período de pandemia veio agravar o abismo socioeconômico existente, expondo alguns grupos sociais, dentre eles os grupos identitários, por justamente não terem acesso a remédios, atendimento médico ou vagas nas UTI dos diversos hospitais públicos desse país e nem mesmo acesso a uma educação que permita a esses grupos entenderem o perigo do vírus.

Sob esse aspecto, o Plano Nacional de Enfrentamento à Covid-19 de 2020, construído por instituições que compõem a Frente pela Vida (2020, p. 33), reafirma essa disparidade:

Os primeiros casos confirmados eram pessoas de estrato econômico elevado, recém-chegados de viagens ao exterior, mas a doença rapidamente atingiu as comunidades pobres das periferias das grandes cidades e passou a se expandir para o interior do País, atingindo inclusive povos indígenas, quilombolas e populações ribeirinhas. A letalidade nesses grupos tem sido superior à média brasileira.

Posto que o atual surto atinge diretamente a população, fazendo com que todos fiquem suscetíveis imunologicamente ao vírus, alguns grupos são mais vulneráveis do que outros, como é o caso dos povos indígenas, tanto do ponto de vista epidemiológico como do social, que são agravantes nessa conjuntura:

O ser humano vulnerável, por outro lado, é aquele que, conforme conceito compartilhado pelas áreas da saúde e assistência social, não necessariamente sofrerá danos, mas está a eles mais suscetível, uma vez que possui desvantagens para a mobilidade social, não alcançando patamares mais elevados de qualidade de vida em sociedade em função de sua cidadania fragilizada. Assim, ao mesmo tempo, o ser humano vulnerável pode possuir ou ser apoiado para criar as capacidades necessárias para a mudança de sua condição. É com base nessa última afirmação que concordamos que não se trata, a vulnerabilidade, apenas de uma condição natural que não permite contestações. Isso porque percebemos que o estado de vulnerabilidade associa situações e contextos individuais e, sobretudo, coletivos. (Carmo \& Guizardi, 2018, p. 6)

Ou seja, sabe-se que a pandemia não é democrática. A vulnerabilidade dos povos indígenas frente à pandemia, no que tange a noção epidemiológica dos grupos indígenas, é descrita também no Plano de Contingência Nacional para infecção do novo coronavírus em povos indígenas do governo federal (Ministério da Saúde, 2020a, p. 3): "As epidemias e os elevados índices de mortalidade pelas doenças transmissíveis contribuíram de forma significativa na redução do número de indígenas que vivem no território brasileiro (...)".

Em suma, essa suscetibilidade originou-se do contato entre indígenas e não indígenas. Desde o início da colonização, as epidemias foram responsáveis pelo extermínio ou dizimação de grande parte da população ameríndia do Brasil e ainda representam uma grande ameaça. A exposição dos povos indígenas ao contato interétnico contribuiu para uma enfática vulnerabilidade, contribuindo atualmente para a dificuldade do enfrentamento do processo pandêmico (Frente Pela Vida, 2020).

É notório que os impactos das epidemias passadas sobressaem em relação aos nativos e, segundo os estudos do Ministério da Saúde (MS), divulgados pelo site da BBC em 2018(Fellet, 2020), $7,2 \%$ dos óbitos de indígenas ocorrem por doenças infecciosas e parasitárias; todavia, entre as crianças, os índices de 2019 apontam que 22,6\% das mortes 
registradas são devidos às doenças respiratórias. Consoante a isso, a Federação dos Povos Indígenas do Mato Grosso (FEPOIMT) justifica no seu Plano Emergencial de Enfrentamento a Covid-19, que as estratégias de combate a essa nova doença devem ser feitas com uma atenção especial aos povos indígenas, pois "a vulnerabilidade em relação a essas patologias historicamente nos revela a extinção de povos, línguas e culturas, além da ameaça ao equilíbrio ambiental e à preservação das florestas" (FEPOIMT, 2020, p. 32).

Os dados do Instituto Brasileiro de Geografia e Estatística (IBGE) indicam que 5,2\% da população brasileira indígenas se encontram no estado de Mato Grosso, representando $1,4 \%$ da população mato-grossense (IBGE, 2010). Segundo a APIB (2021), o Mato Grosso é o segundo estado brasileiro com mais mortes de indígenas pela covid-19. A tabela ${ }^{6}$ abaixo representa o total de óbitos no estado entre março de 2020 e março de 2021:

Quadro $1 \square$ Número de óbitos por covid-19 de indígenas no estado de Mato Grosso

\begin{tabular}{c|c|c}
\hline Mês & $\mathbf{2 0 2 0}$ & $\mathbf{2 0 2 1}$ \\
\hline Jan & - & 04 \\
Fev & - & 02 \\
Mar & - & 04 \\
Abr & - & - \\
Mai & 01 & - \\
Jun & 34 & \\
Jul & 53 & \\
Ago & 38 & \\
Set & 10 & \\
Out & 02 & \\
Nov & 01 & \\
Dez & 07 & \\
\hline
\end{tabular}

Fonte: Comitê Nacional de Vida e Memória Indígena, 2021.

Neste período de tempo, foram totalizadas 156 mortes de indígenas, muitas delas caracterizadas pela sigla SI (Sem Informação) de gênero e/ou aldeia, em resultadoda falta de transparência da Secretária Especial de Saúde Indígena (SESAI). A ausência de informações de raça/cor configura racismo institucional nos serviços de saúde e advém de um processo histórico de apagamento da identidade indígena brasileira, conforme descrito no documento da APIB:

[...] Na perspectiva do movimento indígena, tal processo de apagamento se manifesta de diversas maneiras, como o não atendimento, em muitas regiões do país, de indígenas residentes em áreas urbanas ou em territórios não homologados. Além disso, há o sério problema de falha do preenchimento da informação de raça/cor e povo nos sistemas de informações sobre saúde, bem como o eventual registro de indígenas em outras categorias de cor ou raça, em particular os "pardos", o que pode contribuir para subdimensionar os reais impactos da Covid-19 em populações indígenas. (APIB, 2020, pp. 76-77)

Paralelamente a esse cenário, a cultura comunitária dos povos indígenas inviabiliza a perspectiva do isolamento social, propicia a propagação do vírus nas aldeias, por meio do compartilhamento de utensílios domésticos, dos rituais tradicionais e até mesmo das habitações que podem ter um número elevado de pessoas, conforme é salientado por Urquiza e Pinezi (2020, p. 148):

Outra dificuldade é a concepção de "ficar em casa", prática que não faz parte da tradição indígena. Para muitos desses povos, a casa, sempre muito pequena, é um lugar para dormir. As pessoas passam o dia ao ar livre, buscando alimentos. No caso dos povos indígenas, são culturas da coletividade, passam quase todo o dia em interações intensas. Como propor para essas famílias que devem ficar em casa? [...]

Consoante a isso, o Plano de Contingência específico do DSEI Xingu aborda a temática e descreve os fatores que intensificam as dificuldades de isolamento dentro do território indígena xingu:

O modo de vida dos indígenas favorece a transmissão das viroses respiratórias e em especial do Covid-19. Na maioria das aldeias xinguanas as pessoas vivem em casas comunais, habitadas por famílias extensas, com pouca ventilação. É costume comer com as mãos e compartilhar utensílios como cuias, copos, vasilhas, panelas e talheres. Tanto a forma tradicional de viver dos indígenas da TIX [Território Indígena do Xingu] como precárias condições de saneamento das aldeias, criam condições que favorecem transmissão do SARS CoV-2 projetando um cenário de epidemias de Covid-19 nas aldeias da TIX. (Ministério da Saúde, 2020b, p. 2)

Esse impasse, agravado pela urgência de cumprimento de protocolos de segurança para evitar a disseminação do novo patógeno e a obrigatoriedade do distanciamento social para a população que vive em coletivo, em especial os povos indígenas, amplia as vulnerabilidades e dificultamo controle do vírus nas aldeias.

Santos (2020), ao abordar "A cruel pedagogia do vírus", salienta que: 
Por um lado, ao contrário do que é veiculado pelos media e pelas organizações internacionais, a quarentena não só torna mais visíveis, como reforça a injustiça, a discriminação, a exclusão social e o sofrimento imerecido que eles provocam. Acontece que tais assimetrias se tornam mais invisíveis em face do pânico dos que não estão habituados a ele. (Santos, 2020, p. 21)

Essas invisibilidades reforçam as injustiças existentes, discriminando em relação não só à prevenção, mas também à mitigação da expansão e das consequências do vírus.

Andrey Moreira Cardoso, do Departamento de Endemias da Escola Nacional de Saúde Pública da Fundação Oswaldo Cruz (FIOCRUZ), em entrevista a Christina Queiroz da Revista Pesquisa da Fapesp, chama a atenção para a vulnerabilidade dos povos indígenas diante do SARS-CoV-2, causador da covid19: "Limitações na disponibilidade de territórios tradicionais para manutenção dos modos de vida indígena, de acesso a saneamento básico, bem como infecções recorrentes, desnutrição, anemia e emergência de doenças crônica" (Cardoso, Rodrigues, Luciano \& Mendonça, 2020, p. 45).

Estes indicadores, historicamente, vêm causando vulnerabilidades e colocando em alto risco as populações indígenas, para além de provocarem violências e violações de seus direitos que também se agravaram no último ano.

Em tempos de pandemia, o Estado vem negando direitos territoriais aos indígenas, como fica evidenciado através do Despacho n.o 000137/2020, mencionado na Recomendação 011/20 do Ministério Público Federal (MPF, 2020), onde a Fundação Nacional do Índio (FUNAI) foi orientada para indeferir os deslocamentos de servidores para terras indígenas não homologadas, o que fragiliza o monitoramento da covid-19 nas aldeias e fere o dever da FUNAI de acompanhar as ações de saúde nos territórios indígenas. Outro exemplo é a Instrução Normativa n. ${ }^{0}$ 9/20207, da FUNAI, que autoriza a certificação de propriedades privadas em áreas indígenas não homologadas e terras indígenas interditadas pelo Sistema de Gestão Fundiária (SIGEF) do Instituto Nacional de Colonização e Reforma Agrária (INCRA). Soma-se a isso a pandemia do coronavírus, que agrava as condições desfavoráveis de acesso à saúde e ao saneamento básico, que são a realidade na maioria das comunidades tradicionais.

Santos (2020, p. 25) alerta que: "Haverá mais pandemias no futuro e provavelmente mais graves, e as políticas neoliberais continuarão a minar a capacidade do Estado para responder, e as populações estarão cada vez mais indefesas."

A vulnerabilidade, nesse sentido, é incorporada socialmente, devido à desestruturação de políticas territoriais e específicas no atendimento à saúde, que, apesar de garantidas pelo ordenamento jurí$\mathrm{dico}^{8}$, sofrem com as carências geradas pela apatia governamental nocivas aos povos indígenas.

Outro fator de impacto, destacado pelo Instituto Socioambiental (ISA) e APIB, que foi noticiado: "os números oficiais não refletem necessariamente a extensão da pandemia" (RDNEWS, 2020), devido a falta de dados das subnotificações de indígenas não aldeados. Os mesmos organismos acrescentam que: "Outro problema grave é a ausência de dados sobre indígenas que vivem fora de terras Indígenas homologadas, o que inclui tanto citadinos como populações que aguardam a finalização do longo processo de demarcação de suas terras" (RDNEWS, 2020).

O cenário referente à covid-19 para os povos indígenas é desastroso, pois a realidade exige do Subsistema de Saúde Indígena (SASISUS) uma incorporação dos dados de indígenas que residem nas cidades e que o Subsistema não possui e não fez. E também exige do Sistema Único de Saúde (SUS) um refinamento referente à equidade no acesso aos serviços de saúde, sendo este o grande desafio do SUS ainda por concretizar.

Bruno Latour (2018), em seu ensaio "Down to earth: Politics in the new climatic regime", escreve sobre o atual cenário político, onde a desregulamentação da governança e a ausência do Estado são dois dos fatores que alimentam as desigualdades em tempos de globalização. Os ricos, cada vez mais ricos, não pretendem compartilhar o futuro planeta com os pobres.

Os xinguanos e as específicas vulnerabilidades estruturais para o enfrentamento da covid-19

O Parque Indígena do Xingu (PIX) foi homologado em 1961, para ser um exemplo da política indigenista de cunho protecionista, uma vez que abrigou um complexo cultural e cumpriu a sua atribuição de "cartão postal" do governo durante anos, enquanto a relação com outras áreas indígenas era de indiferença. Na transição entre o bioma cerrado e a Amazônia, o PIX compreende uma área de cerca de 2,8 milhões de hectares, situado na região nordeste do estado de Mato Grosso, e ampara dezesseis (16) etnias indígenas, sendo, explicitamente, fonte de proteção aos povos que viviam ameaçados pelos interesses dos não indígenas (ISA, 2011, pp. 20-21).

Com base em uma pesquisa desenvolvida por profissionais do Instituto Brasileiro de Geografia e Estatística (IBGE), foi formulado um caderno de insumos sobre a Vulnerabilidade Demográfica e Infraestrutural das Terras Indígenas à Covid-19 (2020). A partir de dados anteriores à pandemia publicados pelo próprio instituto, foi construído um índice de Vulnerabilidade Demográfica e Infraestrutural das Terras Indígenas (IVDIC), para facilitar 
as ações preventivas de saúde indígena durante a pandemia, que são classificadas conforme as seguintes variáveis:

a) PI - Percentual de pessoas idosas na Terra Indígena;

b) MEDMOR - Média de moradores por domicílio da Terra Indígena;

c) SEBX - Existência de banheiro de uso exclusivo ou sanitário nos domicílios da Terra Indígena;

d) SRED - Rede de abastecimento de água nos domicílios da Terra Indígena;

e) MUTI - Localização da Terra Indígena em relação aos municípios com disponibilidade de leitos em UTI;

f) SITTI - Estado da situação de regularização da Terra Indígena. (Azevedo, Damasco, Antunes, Martins \& Rebouças, 2020, p. 6)

Considerando que a análise de vulnerabilidade das terras indígenas (TI) tem por objetivo oferecer subsídio para as implementações de políticas públicas no panorama da covid-19, ao aplicar o IVDIC nas TI, constata-se que o Distrito Sanitário Especial Indígena do Xingu apresenta um nível de vulnerabilidade crítica mediante as variáveis supracitadas (Azevedo, Damasco, Antunes, Martins \& Rebouças, 2020).

Segundo o censo demográfico do IBGE de 2010, mecanismo do qual a pesquisa é submetida, os IVDIC no Parque Indígena do Xingu (PIX) apresentam as seguintes taxas:

- Pessoas Idosas (PI): ponderando que a coleta de dados foi feita com pessoas acima de 50 anos, o PIX enquadra-se na média geral de $10,43 \%$ das TI (Azevedo, Damasco, Antunes, Martins \& Rebouças, 2020). Ressalta-se que a vulnerabilidade desse grupo em relação às comorbilidades, ou seja, o conjunto de doenças que uma pessoa apresenta e que está presente comumente na população idosa, pode levar a complicações graves mediante a infecção da covid-19;

- Média de Moradores por Domicílio (MEDMOR): nas TI é superior à nacional, mas cabe enfatizar que no PIX essa média ultrapassa a estimativa geral, superando a marca de sete moradores por domicílio; isso significa que, quando o vírus entra nas aldeias, a disseminação ocorre de maneira descontrolada (Azevedo, Damasco, Antunes, Martins \& Rebouças, 2020);

- Existência de Banheiros de uso Exclusivo (SEBX): a média de domicílios das TI sem o uso desse aspecto sanitário é de 30,5\%, enquanto a nacional é de $6,2 \%$. Essa disparidade é ainda maior em algumas áreas indígenas, como o próprio PIX, que apresenta mais de $90 \%$ dos domicílios sem a SEBX (Azevedo, Damasco, Antunes, Martins \& Rebouças, 2020);

- Rede de abastecimento de água (SRED): é extremamente escassa nas comunidades indígenas, com mais de $270 \mathrm{TI}$, dentre elas o Xingu, que apresenta cerca de $100 \%$ dos domicílios sem acesso à rede; essa carência causa preocupações nas estratégias de prevenção ao coronavírus, tendo em vista que o ato de lavar as mãos é a principal medida de combate (Azevedo, Damasco, Antunes, Martins \& Rebouças, 2020);

- Estado da situação de regularização da TI (SITTI): é de fundamental importância, pois a saúde dos povos indígenas está intimamente ligada à terra, e é a partir dela que são criados subsídios para sua existência (Azevedo, Damasco, Antunes, Martins \& Rebouças, 2020). O PIX, por sua vez, é um território demarcado; das $471 \mathrm{TI}$ analisadas pelo censo em 2010, somente oito estão homologadas, 28 estão declaradas e 435 perduram ainda sem a titulação.

No mapa da página ao lado, é possível visualizar a soma de fatores que tornam a população do Parque Xingu (número 32 do mapa), bem como de outras áreas indígenas, mais vulnerável à covid-19.

Os demais Distritos Sanitários Especiais Indígenas do Mato Grosso apresentam, em sua maioria, um nível de vulnerabilidade intenso ou crítico, segundo os parâmetros supracitados. Conforme a Figura 1, o DSEI Xavante (número 31) é caracterizado, tal como o DSEI Xingu, como crítico segundo a análise do IVDIC. Já a vulnerabilidade intensa é atribuída aos DSEI Cuiabá (número 26), Kaiapó-MT (número 34) e Araguaia (número 8); por fim, o DSEI Vilhena (número 30) é o único distrito do Mato Grosso definido como de alta vulnerabilidade.

Fica evidente a necessidade de caracterização dos povos indígenas em situação de extrema vulnerabilidade diante da pandemia. Essa identificação é importante para que haja a priorização nas ações governamentais e o cumprimento de estratégias específicas para garantir a subsistência dos povos indígenas em todo território nacional. Dar visibilidade a essas vulnerabilidades é também falar das desigualdades sociais e das questões relacionadas à justiça. Trata-se de falar, por um lado, de quem ganha e de quem perde e quais intervenções foram realizadas para moderar essas antigas fragilidades e, por outro, da inação política diante da precariedade social extrema.

Para Beck (2018), existe uma "política da invisibilidade" promovida por alguns governos com pregações de inverdades, cujo o objetivo seria 
Figura $1 \triangleright$ Distritos Sanitários Especiais Indígenas (Centro-Sul): Vulnerabilidade ao COVID 19 nas Terras Indígenas

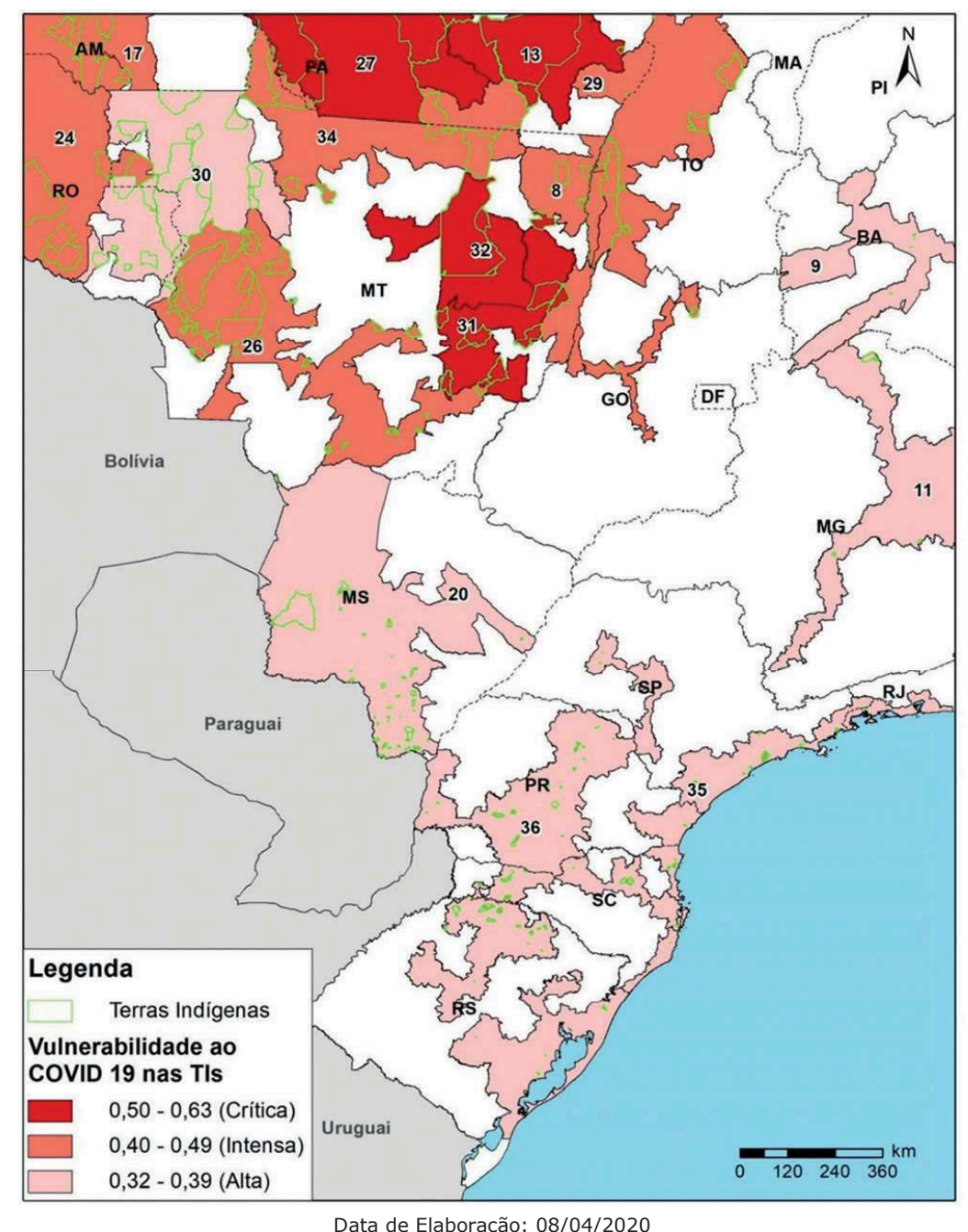

Fontes: IBGE, Censo Demográfico 2010; FUNAI, 2010 e 2019; DATASUS/CNES, 2020, SESAI, 2019.

o de suprimir grupos identitários, por exemplo, com políticas contrárias a estes numa tentativa de eliminar essas pessoas. Inclusive, o autor salienta que um dos efeitos dessa política da invisibilidade é "promover falsos debates onde há consenso científico, silenciando críticos, orquestrando estudos para neutralizar mesmo fortes evidências de danos" (Beck, 2018, p. 188).

\section{A Política Nacional de Atenção à Saúde Indígena (PNASPI): a estrutura e situação epidemiológica do estado de Mato Grosso}

A Política Nacional de Atenção à Saúde dos Povos Indígenas (PNASPI) foi formulada partindo do pressuposto de que a saúde é direito de todos e dever do Estado, conforme descrito no art. 169 da Constituição Federal de 1988 (Brasil, 1988). O propósito preponderante dessa política é integrar as comunidades indígenas no Sistema Único de Saúde (SUS) de forma equitativa. Para tal fim, pretende-se considerar a realidade vulnerável dessas populações com o propósito de "remediar", dar suporte às dificuldades sanitárias e reconhecer o direito à cultura para preservação dos aspectos tradicionais e das diversidades culturais, sociais, geográficas, históricas e políticas de cada etnia (FUNASA, 1999 a 2002c).

Partindo de uma perspectiva histórica, a assistência à saúde no Brasil, nas décadas de 1970 e 1980 , sempre foi tratada com descaso no que tange à população indígena. A falta de responsabilidade estatal nas ações sanitárias para as comunidades era atrelada a uma política integracionista ${ }^{9}$ de negação do reconhecimento da sua existência. Os órgãos protetivos indigenistas, como o Serviço de Proteção aos Índios (SPI), criado em 1910, e a 
Fundação Nacional do Índio (FUNAI), criada em 1967, compactuavam com o viés de anulação dessa população e o ideal de que os indígenas são "relativamente incapazes", presentes no Código Civil de $1916^{10}$. Dessa maneira, a ideia de homogeneidade cultural era disseminada na política indigenista do Governo, conforme descrito pela cartilha do Conselho Indigenista Missionário (CIMI):

As políticas implementadas desde o período colonial visavam à integração ou ao extermínio dos mais diferentes povos, e a perspectiva de integração destes à sociedade nacional justificou diversas ações etnocidas. Considerados "entraves ao desenvolvimento", o destino dos povos indígenas sempre foi traçado nos termos do dominador. O direito de existência futura, com distintos modos de pensar, de organizar-se e relacionar-se com o mundo, sempre Ihes foi negado. A falta de políticas públicas relativas à educação e saúde, e a demarcação de territórios insuficientes para o modo de vida tradicional, são respostas históricas com premissas integracionistas. Não é à toa que o atendimento à saúde restringe-se a medidas paliativas e emergenciais. (Altini, Rodrigues, Padilha, Moraes \& Liebgott, 2013, p. 7)

Assim, o Conselho Missionário Indigenista (CIMI) aponta que, desde o período colonial, as políticas foram marcadas pela polaridade "integração ou extermínio". As políticas de educação e saúde trazem, em seu bojo, premissas integracionistas, pois uma política de saúde que não inclui os itinerários dos cuidados das medicinas indígenas não se compromete com a atenção diferenciada.

O árduo processo em prol da luta por uma atenção diferenciada à saúde dos povos indígenas resultou no sancionamento da Lei n. ${ }^{\circ} 9.836,23$ de setembro de 1999, chamada Lei Arouca, que criou o Subsistema de Atenção à Saúde Indígena, componente do Sistema Único de Saúde (SUS). A implementação de tal sistema significou a concretização dos direitos à saúde indígenas atribuídos na Constituição Federal de 1988.

Conforme as diretrizes estabelecidas pela PNASPI, a operacionalização do sistema fica a cargo dos 34 DSEI, que atuam conforme a região geográfica, isto é, de acordo com a quantidade de habitantes e etnias na comunidade indígena visando a descentralização do atendimento primário à saúde.

A organização estrutural de atendimento primário à saúde dos DSEI conta com os seguintes mecanismos: os postos de saúde nas comunidades sob responsabilidade dos Agente Indígenas de Saúde (AIS), que promovem o acompanhamento, a promoção e a prevenção básica; os polos-base, que podem ser localizados em centros de referên- cia e possuem uma equipe multidisciplinar, que na maioria dos casos é composta por médicos, enfermeiros, dentistas e auxiliar de enfermagem; e as Casas de Saúde dos Índios (Casais), localizadas nos município para serem locais de recepção e apoio aos indígenas quando há necessidade de atendimento hospitalar específico nos hospitais de referência do SUS.

A implementação da PNASPI no território do Xingu e os planos de enfrentamento a covid-19 no estado de Mato Grosso

A criação do Parque Indígena do Xingu (PIX) foi um esforço conjunto na elaboração da proposta na qual trabalharam: Darcy Ribeiro, Noel Nutels, Roberto Cardoso de Oliveira e Eduardo Galvão. A partir desta proposta, foi organizada uma comissão composta pelo vice-presidente Café Filho, Marechal Rondon, Heloisa Alberto Torres (diretora do Museu Nacional), José Maria da Gama (diretor do SPI), Noel Nutels e irmãos Villas Bôas. O Projeto n. ${ }^{\circ} 14$, de 1953, foi apresentado no Congresso Nacional no dia 20 de março de 1953, passando por vários embates políticos e interesses econômicos envolvendo as empresas colonizadoras no estado de Mato Grosso,. Sua aprovação só ocorreu em 1961 pelo Presidente Jânio Quadros, que assinou o decreto que fundou o Parque Nacional do Xingu, bem como outros parques; poucos anos depois, o Parque Nacional do Xingu foi reconhecido como Parque Indígena do Xingu. Cabe registrar que esse Parque trouxe, em sua proposta, uma relação umbilical entre os indígenas e o território dotado de recursos ambientais que asseguram sua reprodução sociocultural, e teve como principais objetivos: "a) preservar física e culturalmente os povos indígenas que lá viviam; b) acolher grupos indígenas ameaçados de extinção por conflitos com as frentes invasoras de suas terras; c) preservar o meio ambiente, a fauna e a flora da região" (Baruzi, 2007, p. 184).

A criação do Parque Indígena do Xingu configurou um projeto ousado, pois a figura jurídica de parque indígena ainda não existia; assim, foi proposta a criação de uma reserva indígena de grande extensão territorial, apoiada na figura jurídica de um parque nacional.

Sob o aspecto da estruturação dos serviços de saúde, o Projeto Xingu, da Escola Paulista de Medicina da Universidade Federal de São Paulo (EPM/ UNIFESP), participa ativamente desde a década de 1980 na implementação sanitária assistencial do Parque Indígena do Xingu. Baruzzi e Junqueira (2005, p. 72 ), idealizadores do projeto que tem como intuito conservar a medicina tradicional local, acentuam os desafios na saúde indígena mediante o aspecto cultural da comunidade: 
O desafio não é simplesmente implantar no Parque um modelo de assistência à saúde calcado na medicina ocidental, com mera transferência de tecnologia e locação de recursos. O real desafio é trazer benefícios à saúde do índio sem causar danos irreversíveis à sua cultura, sem destruir suas crenças e sua medicina tradicional. (Baruzzi \& Junqueira, 2005, p. 72)

O processo de implementação do modelo de vigilância da saúde preconizou, diante do exposto, uma construção em conjunto com os povos xinguanos, trabalhando a interculturalidade de modo a estruturar uma linha de diálogo entre os profissionais e os usuários que inclui a capacitação dos Agentes Indígenas de Saúde (AIS) e dos Auxiliares de Enfermagem Indígena (AEI); após a efetivação do DSEI Xingu, houve novas capacitações entre 2005 e 2019.

Entretanto, após a criação da Secretaria Especial de Saúde Indígena (SESAI), em 2010, o seu vínculo direto com o Ministério da Saúde possibilitou o aumento do número de profissionais de saúde, como é o caso do Programa Mais Médicos, que atuam nas comunidades indígenas ampliando o acesso ao serviço de saúde. Consequentemente, verificaram-se resultados positivos em algumas localidades, divergindo do caso do DSEI Xingu, que, ao romper com o modelo de vigilância em saúde e voltar o seu foco para o atendimento biomédico com profissionais sem a devida preparação, reduziu a participação dos AIS nas tomadas de decisão e planejamento (Mendonça, Rodrigues \& Pereira, 2019).

Consoante as lacunas na Política Nacional de Saúde Indígena, o agravamento da covid-19 fez com que fossem criados Planos de Contingenciamentos para os povos indígenas. Tais medidas constam nos âmbitos nacional e específicos elaborados pelos DSEI. Em suma, são documento repetitivos e sem detalhamento das ações concretas de combate para a especificidade de cada povo. Neles são descritos os níveis de resposta, com deliberações a serem adotadas perante o risco do local. No entanto, a superficialidade dos planos distritais, sobretudo o elaborado para o Xingu, não define as atuações de forma precisa, como, por exemplo; qual o protocolo adotado caso seja necessária a remoção de um indígena da aldeia; onde será realizada a barreira sanitária; de que forma os profissionais de saúde entrarão nas comunidades sem colocá-las em risco de contágio. Essas e outras orientações são necessárias para a eficiência do plano e não foram contempladas.

Rodrigues (2020) declara que a política de combate ao SARS-Cov-2 em área indígena deve se adequar à realidade indígena: "As comunidades que conseguem subsistir com atividades de caça, pesca e coleta devem permanecer isoladas. Já outras que dependem das cidades para obter alimentos necessitam ser abastecidas, evitando o deslocamento de indígenas dos territórios" (Rodrigues, 2020, p. 47).

Esta declaração deixa claro as inúmeras realidades de tempo de contato com a sociedade envolvente, bem como a proximidade ou não das cidades.

Segundo o Plano de Contingência do DSEI Xingu, o território localizado ao norte do Mato Grosso inclui 114 aldeias, que contam com quatro polos-base onde se encontram as Equipes Multidisciplinares de Saúde Indígena (EMSI). Esses polos-base são: Leonardo, que abrange 51 aldeias; Diauarum, 44 aldeias; Pavuru, 15 aldeias; e Wawi, 4 aldeias. Além disso, há quatro regiões estratégicas situadas entre os polos-base mais populosos devido à discrepância do número de aldeias (Ministério da Saúde, 2020b, p. 4).

Os primeiros casos de covid-19 no PIX foram confirmados em 6 de junho de 2020, e dias depois um bebê que fazia parte das aldeias kalopalo foi o primeiro óbito registrado na terra indígena do Xingu. O vírus se alastrou pelas aldeias, e a subnotificação dos dados tornou-se um problema corriqueiro, como é salientado no documento da organização Frente pela Vida (2020, p. 80 ):

As informações sobre o efeito da pandemia nos povos indígenas são invisibilizadas pelos dados oficiais da Sesai, pois consideram somente os grupos atendidos pelos DSEI, e as secretarias municiais e estaduais não têm consolidado os dados de cor/raça. Diante desse cenário, as organizações indígenas têm realizado monitoramento dos casos confirmados e óbitos de indígenas de forma autônoma para visibilizar os impactos da COVID-19.

Corroborando as afirmações da Frente pela Vida, a médica sanitarista Sofia Mendonça (2020) afirma que "os distritos sanitários indígenas nem sempre são contabilizados nos planos de contingência de estados e municípios" (Mendonça, Rodrigues \& Pereira, 2019, p. 48); portanto, os DSEI ficam de fora do planejamento.

No documento da Articulação dos Povos Indígenas do Brasil, é relatada a situação enfrentada pelos xinguanos no ápice da covid-19 no país (APIB, 2020, p. 29):

O Território Indígena do Xingu foi devastado pela primeira onda da pandemia do coronavírus. De acordo com matéria da Carta Capital, além da tristeza pelas mortes, há a revolta expressa, principalmente, em críticas à atuação do médico-chefe do Polo-Base Leonardo Villas Boas, maior unidade de saúde da região. Lá, morreram 13 de 14 indígenas vítimas do coronavírus no Distrito Sanitário Especial Indígena (DSEI) Xingu, em Canarana (MT). A taxa de 
letalidade do Xingu é a terceira maior entre

todas as terras indígenas brasileiras.

Os boletins epidemiológicos, disponibilizados pelo DSEI Xingu durante o período de 21 de setembro a 14 de outubro, mostram um crescimento considerável no número de casos de covid-19 do polo-base Leonardo, que detém um maior número de aldeias; durante esses 24 dias houve ocorreu o óbito de um indígena do Xingu. No entanto, o terceiro polo-base em número de aldeias, o Pavuru, apresentou um aumento de 16 casos nessas quatro semanas de análise; já o polo-base Diauarum teve 6 casos confirmados, mas em contrapartida o número de indígenas recuperados da covid-19 surpreendeu positivamente, totalizando 31 casos; o único polo-base em número estável foi o Wawi. Com base nisso, o gráfico abaixo dispõe dos dados de casos confirmados de coronavírus no território Xingu: podem ser tratados em domicílio ou em uma estrutura de saúde que tenha recursos básicos para o manejo adequado da doença. Cerca de $20 \%$ dos casos evoluem para formas moderadas ou graves, necessitando de maiores cuidados. Desses casos moderados e mais graves, cerca de um quarto ( $5 \%$ do total de doentes) irá precisar de suporte ventilatório em hospitais e Unidades de Terapia Intensiva (UTI). (FEPOIMT, 2020 p. 22).

No caso do Parque Indígena do Xingu (PIX), não há necessidade de novas unidades de atendimento; no entanto, a falta de insumos, a demanda de medicamentos e a reposição de materiais são as necessidades do DSEI (FEPOIMT, 2020, p. 46).

Gráfico $1 \triangleright$ Casos de covid-19 no Dsei Xingu

\section{Casos Confirmados por Semana Epidemiológica}

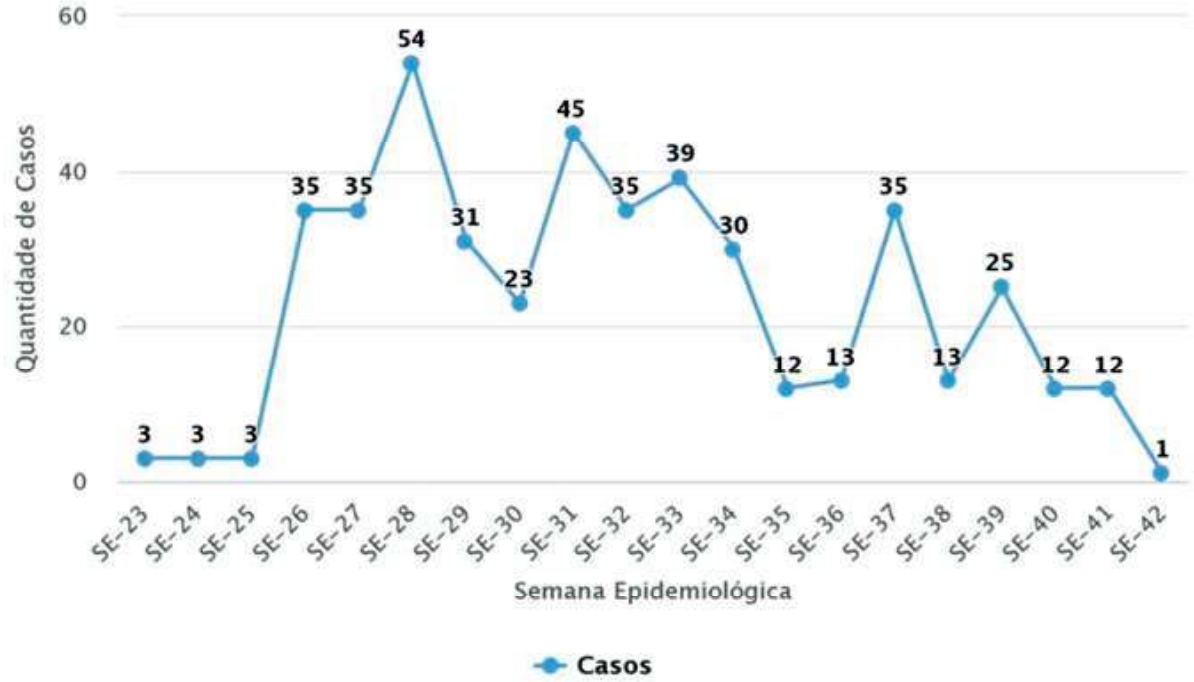

Fonte: Fichas de notificação e resultados laboratoriais, DIASI/DISEI/XINGU-MT/SESAI/MS, 2020.

O território do Xingu e as demais áreas indígenas do Mato Grosso enfrentam o avanço do coronavírus e, com isso, a necessidade de medidas para uma maior eficácia no atendimento à saúde. A Federação de Povos e Organizações Indígenas do Mato Grosso (FEPOIMT) propôs a implementação de unidades para isolamento e tratamento das infecções respiratórias em pontos estratégicos dos territórios, segundo o seu plano de enfrentamento à covid-19:

Aproximadamente $80 \%$ dos casos de COVID-19 apresentam sintomas leves, que

\section{Considerações finais}

O tema da pesquisa, "A situação de vulnerabilidade dos povos indígenas do Mato Grosso e em especial dos xinguanos frente à covid-19 e às omissões estatais", escolhido para a construção deste artigo científico denota as condições sociais e de suscetibilidade que tornam os povos indígenas vulneráveis à pandemia pelo novo coronavírus. O alastramento do vírus nas aldeias se reflete nas vulnerabilidades epidemiológica e social enfrentadas por esses grupos. Historicamente os povos indígenas convivem com o risco de genocídio por causa 
de epidemias e, atualmente, por causa do novo coronavírus. Devido à falta de políticas específicas no atendimento à saúde no cenário atual, esse vírus tem se alastrado rapidamente.

Com enfoque no estado de Mato Grosso, a ineficácia das ações protetivas emergenciais e as omissões governamentais impactaram no crescente índice de casos e óbitos decorrentes da covid-19. Dados da APIB comprovam que a taxa de letalidade por covid-19 nos povos indígenas é de $9,6 \%$, por comparação com a da população brasileira, que é de 5,6\%, evidenciando e agravando ainda mais a política anti-indígena, que não implementou de forma eficaz um plano de ação para combater a covid-19 nos territórios indígenas.

A importância do tema abordado é irrefutável, considerando que o assunto envolve o risco de genocídio de povos indígenas em face da atual crise sanitária. Concluindo, este estudo analisa os efeitos nocivos que a pandemia da covid-19 e as omissões governamentais tiveram no agravamento da vulnerabilidade dos indígenas do estado de Mato Grosso.

\section{Notas}

1 O Decreto Legislativo n. ${ }^{\circ}$ 6, de 18 de março de 2020, "reconheceu a ocorrência de calamidade pública, conforme o art. 65 da Lei Complementar n. ${ }^{\circ} 101$ de 04 de maio de 2000, nos termos da solicitação do Presidente da República encaminhada por meio da Mensagem n.0 93, de 18 de março de 2020" (Brasil, 2020). Disponível em <http://www.planalto.gov.br/ccivil_03/portaria/ DLG6-2020.htm>. Acesso em: 16 de mar. 2021.

2 Sobre dados da letalidade da covid-19 em relação aos povos indígenas, ver Tomas, 2020. Ver também: Gilbert, 2020.

3 Segundo Albuquerque (2020), existem oito Propostas de Emendas à Constituição e 17 projetos de leis tramitando em conjunto com as PEC diretamente ligadas à supressão de direitos indígenas.

4 Para obter maiores informações: APIB, 2021.

5 Acesse o link para mais informações: https://emergenciaindigena.apiboficial.org/dados_covid19/.

6 As fontes dos dados são: Organizações indígenas de base da APIB, Frentes de enfrentamento à covid-19 organizadas no Brasil que colaboram com a APIB, SESAI, Secretarias Municipais e Estaduais de Saúde e Ministério Público Federal (APIB, 2021).

7 Tal instrumento foi objeto de liminar na ação civil pública n. 0 1007376-21.2020.4.01.3600 movida pelo MPF.

8 Com o advento da Lei n.० 9.836, de 23 de setembro de 1999, foi adotado o subsistema do SUS destinado aos indígenas, cuja denominação é Subsistema de Atenção à Saúde Indígenas (SASISUS).

9 Segundo o dicionário online Infopédia, integracionista é toda política relativa a integração de duas ou mais nações numa só entidade política. Integracionista in Dicionário infopédia da Língua Portuguesa. Porto: Porto Editora, 2003-2021. Disponível em: https://www.infopedia.pt/ dicionarios/lingua-portuguesa/integracionista. Acesso em 15.mai. 2021.
10 Segundo o art. 6, inciso III do Código Civil (Lei n. ${ }^{\circ}$ 3.071/16), os silvícolas, ou seja, os indígenas, são relativamente incapazes de exercer certos atos, determinando a sua tutela por um órgão indigenista estatal (Serviço de Proteção aos Índios - SPI), até que sejam integrados à "civilização do país" (Brasil, 1961).

\section{Referências bibliográficas}

Albuquerque, A. A. U. do L. (2020). As violações aos direitos indígenas frente à constituição federal de 1988. Revista Unifeso - Humanas e Sociais, 5(5), 68-94.

Altini, E., Rodrigues, G., Padilha, L., Moraes, P. D., \& Liebgott, R. A. (orgs.) (2013). A política de atenção à saúde indígena no Brasil: Breve recuperação histórica sobre a política de assistência à saúde nas comunidades indígenas. Brasília: Conselho Indigenista Missionário - CIMI.

APIB. (2020). Nossa luta é pela vida. Covid-19 e povos indígenas: O enfrentamento das violências durante a pandemia. Comitê Nacional pela Vida e Memória Indígena.

APIB. (2021). Emergência indígena. Retirado de https:// emergenciaindigena.apiboficial.org/dados_covid19/

Azevedo, M., Damasco, F., Antunes, M., Martins, M. H., \& Rebouças, M. P. (2020). Análise de vulnerabilidade demográfica e infraestrutural das terras indígenas à covid-19. Apublica. Retirado de https://apublica.org/wp-content/uploads/2020/04/ caderno-demografia-indigena.pdf

Brasil. (1961). Código Civil. Lei n.o 3.071 de $1 .^{\circ}$ de janeiro de 1916. Brasília: Senado Federal.

Brasil. (1988). Constituição da República Federativa do Brasil. Brasília: Senado Federal, Centro Gráfico.

Baruzzi, R. G. (2007). A universidade na atenção à saúde dos povos indígenas: A experiência do Projeto Xingu da Universidade Federal de São Paulo/ Escola Paulista de Medicina. Saúde e Sociedade, $16(2), 182-186$

Baruzzi, R. G., \& Junqueira, C. (2005). Parque Indígena do Xingu: Saúde, cultura e história. São Paulo: Terra Virgem.

Brasília. (1993). II Conferência Nacional de Saúde para os Povos Indígenas. Retirado de http:// bvsms.saude.gov.br/bvs/publicacoes/2 conferencia_nacional_saude_povos_indigenas_relatorio_final.pdf

Beck, U. (2018). A metamorfose do mundo: novos conceitos para uma nova realidade (1. a ed.). Rio de Janeiro: Zahar.

Carmo, M. E. do, \& Guizardi, F. L. (2018). O conceito de vulnerabilidade e seus sentidos para as políticas públicas de saúde e assistência social. Cadernos de Saúde Pública, 34(3).

Cardoso, A., Rodrigues, D., Luciano, G., \& Mendonça, S. (2020). Problemas crônicos de saúde e falta de articulação do poder público representam desafios no combate ao vírus SARS-CoV- 2 em territórios indígenas. [Entrevista cedida a] Christina Queiroz. Pesquisa FAPESP, (291), 45-50. Retirado de https://revistapesquisa.fapesp.br/vulnerabilidade-historica-2/ 
Fausto, C. (2020, 25 de abril). O sampo do tempo do meu avô: Memórias do etnocídio na pandemia. Nexo Jornal. Retirado de https://www.nexojornal. com.br/ensaio/debate/2020/O-sarampo-do-tempo-de-meu-av\%C3\%B4-mem\%C3\%B3rias-do-etnoc\%C3\%ADdio-na-pandemia

Fellet, J. (2020, 25 de março). Coronavírus pode dizimar povos indígenas, diz pesquisadora. $B B C$ News, Brasil. Retirado de https://www.bbc.com/ portuguese/brasil-52030530

Frente pela Vida. (2020). Plano Nacional de Enfrentamento à Pandemia da Covid-19. Frente pela Vida.

Federação dos Povos Indígenas do Mato Grosso. (2020). Plano emergencial de enfrentamento ao coronavírus - Covid-19 - para os povos indígenas de Mato Grosso. Cuiabá: Fepoimt

Gilbert, D. (2020, 23 de maio). O coronavírus está matando povos indígenas isolados numa taxa de letalidade alarmante. VICE. Retirado de https:// www.vice.com/pt/article/ep4ngz/o-coronavirus-esta-matando-povos-indigenas-isolados-numa-taxa-alarmante

Instituto Brasileiro de Geografia e Estatística (IBGE). (2012). Os indígenas no Censo Demográfico 2010. Rio de Janeiro: IBGE. Retirado de https://www. ibge.gov.br/indigenas/indigena_censo2010.pdf

Instituto Socioambiental (ISA). (2011). Almanaque Socioambiental Parque Indígena do Xingu: 50 anos. São Paulo: ISA.

Latour, B. (2018). Down to Earth: Politics in the new climatic regime. Cambridge: Polity Press. Retirado de http://www.bruno-latour.fr/node/754.html

Mahase, E. (2020). Coronavirus: Covid-19 has killed more people than SARS and MERS combined, despite lower case fatality rate. The $B M J,(368), 1-1$.

Mendonça, S. B. M, Rodrigues, D., \& Pereira, P. P. G. (2019). Modelo de atenção à saúde indígena: $O$ caso do DSEI Xingu. Cadernos de Saúde Pública, (35). Retirado de http://cadernos.ensp.fiocruz. $\mathrm{br} / \mathrm{csp} /$ artigo/816/modelo-de-atencao-a-saude-indigena-o-caso-do-dsei-xingu

Ministério Público Federal (MPF). (2020). Recomendação n. ${ }^{\circ} 11$ de 2020. Retirado de http://www.mpf. $\mathrm{mp} . \mathrm{br} / \mathrm{df} / \mathrm{sala}$-de-imprensa/docs/RecomendacaoSaudeIndigenaCOVID19.pdf

Ministério da Saúde. (2020a). Plano de Contingência Nacional para Infeç̧ão Humana pelo novo Coronavírus (COVID-19) em Povos Indígenas. Brasília: Ministério da Saúde, Secretaria Especial de Saúde Indígena.

Ministério da Saúde. (2020b). Plano de contingência para infecção humana pelo novo coronavírus Covid19. Canarana: Ministério da Saúde, Secretaria de Vigilância em Saúde.

RDNEWS Portal de Notícias de MT (2020). Mais de 60\% das mortes por Covid-19 em Porto Esperidião são de chiquitanos saiba. Retirado de https://www. rdnews.com.br/coronavirus/conteudos/131547

Rodrigues, G. (2020, 06 de junho). Primeiro centro de medicina indígena do AM, o Bahserikowi'i, é inaugurado em Manaus. Diário do Amazonas. Retirado de https://d24am.com/amazonia/ centro-de-medicina-indigena-o-bahserikowii-einaugurado-em-manaus/

Sato, M. (coord). (2020). Os condenados da pandemia. Cuiabá: GPEA-UFMT.

Santos, B. de S. (2020). A cruel pedagogia do vírus. Coimbra: Almedina.

Tomas, J. A. (2021, 26 de junho). O drama dos índios em meio ao surto de coronavírus. VEJA. Retirado de https://veja.abril.com.br/brasil/o-drama-dos-indios-em-meio-ao-surto-de-coronavirus

Urquiza, A. H. A., \& Pineza, A. K. M. (2020). As culturas do confinamento: Um olhar da crise, a partir da realidade dos povos indígenas. Bauru, 8(2), 143-157.

World Health Organization (WHO). (s.d.). Severe acute respiratory syndrome (SARS). Retirado de https:// www.who.int/csr/sars/en/

Recebido a 25/05/2021. Aceite para publicação a 08/10/2021.

Cláudia Maria Guimarães Lopes de Castro. Assistente Social da Secretaria de Saúde do Estado de Mato Grosso, no Escritório Regional de Saúde de Cáceres e na Comissão de Integração Ensino/Serviço. Doutora em Estudo de Cultura Contemporânea (Programa de Pós-Graduação em Cultura Contemporânea - ECCO/UFMT). Equipe do Projeto de Pesquisa Observatório de Políticas Públicas sobre a covid-19 para povos e comunidades tradicionais (UNEMAT). Cáceres-MT, Brasil. ORCID: http://orcid.org/0000-0001-6074-5424. Email: claudiapesquisadora@gmail.com Vívian Lara Cáceres Dan. Docente adjunta do Curso de Direito, vinculado a Faculdade de Ciências Exatas e Tecnológicas, do campus de Barra do Bugres, da Universidade do Estado de Mato Grosso (UNEMAT). Coordenadora do Projeto de Pesquisa Observatório de Políticas Públicas sobre a covid-19 para povos e comunidades tradicionais (UNEMAT). Barra do Bugres-MT, Brasil. ORCID: http://orcid.org/0000-0001-9880-3028. Email: vivian.dan@unemat.br Évelin Mara Cáceres Dan. Docente adjunta do Curso de Direito, vinculado a Faculdade de Ciências Exatas e Tecnológicas, do campus de Barra do Bugres, da Universidade do Estado de Mato Grosso (UNEMAT). Equipe do Projeto de Pesquisa Observatório de Políticas Públicas sobre a covid-19 para povos e comunidades tradicionais (UNEMAT). Barra do Bugres-MT, Brasil. ORCID: http://orcid.org/0000-0001-9960-6325. Email: evelindan@unemat.br Eduarda Cristine Pedro Arruda. Acadêmica do Curso de Direito vinculado a Faculdade de Ciências Exatas e Tecnológicas, do campus de Barra do Bugres, da Universidade do Estado de Mato Grosso (UNEMAT). Bolsista do Projeto de Pesquisa Observatório de Políticas Públicas sobre a covid-19 para povos e comunidades tradicionais (UNEMAT). Barra do Bugres-MT, Brasil. ORCID: http://orcid.org/0000-0001-8111-5181. Email: eduarda.arruda@unemat.br 